\title{
Terminal branch density and fruit production in the canopy of high-yield mango orchards
}

\author{
L.E.C. de Sousa Ferraz ${ }^{1}$, Í.H.L. Cavalcante ${ }^{2}$, J. Teixeira Lobo² and J. Gomes da Cunha² \\ ${ }^{1}$ Clorofila Agropecuária, Petrolina, Brazil \\ ${ }^{2}$ Federal University of São Francisco Valley, Petrolina, Brazil
}

\section{Summary}

Mango tree growth habit depends on cultivar, thus branch density also varies as sparse, medium and dense, but environmental conditions and pruning present particular importance since light penetration influence vegetative growth, flower initiation, fruit set, and, consequently, fruit yield. Mango canopy access to sun light has direct correlation with production branches. Thus, an experiment was carried out to evaluate the terminal branches density and fruit production in the plant canopy of high yield mango cv. 'Tommy Atkins' orchards in Brazilian semiarid. The experimental design consisted of randomized blocks with treatments defined as three parts of the canopy (upper, middle or lower) and two plant sides (East and West), with eighteen replications and ten plants in each parcel. The following variables were evaluated: i) terminal branches density (number of terminal branches $\mathrm{m}^{-2}$ ); ii) fruit density (number of fruits $\mathrm{m}^{-2}$ of the canopy); and iii) number of fruits per terminal branch. Mango plants mechanically pruned in trapezoidal form the number of terminal branches, branch density, fruit density and the number of fruits per branch depend on plant side (East and West) and plant position in the canopy; terminal branches and fruit production is concentrated in the West side of the plant and in the lower part of the canopy; in a high yield mango orchard pruned in trapezoidal form, the number of fruits per terminal branch is $\mathbf{1 . 1 5}$.

Keywords

Mangifera indica L., pruning, plant architecture, fruit number, light availability, vegetative area

\section{Introduction}

Brazil is the seventh most producing country for mangoes in the world (FAO, 2017), and one of the largest mango exporter countries, with almost $10 \%$ of the world mango market (FAO, 2017). Brazilian mango is especially grown in the São Francisco Valley, a region with tropical semiarid climate that accounts for $85 \%$ of Brazilian exports of fresh mango (VALEXPORT, 2016).

Mango growth is rhythmic, with major competition between intermittent vegetative growth and flowering, thus external stimulus especially by pruning and other agronomic techniques (water stress, nutrient management, gibberellin inhibition and flowering induction) have favorable response to reach high yields (Ramirez and Davenport, 2016; Barbosa et al., 2016; Cavalcante et al., 2018). Among these factors,

\section{Significance of this study}

What is already known on this subject?

- It is already known that mango fruit production in commercial orchards is a crucial agronomical practice and light availability for branches and buds affects flower induction.

\section{What are the new findings?}

- In a high-yield mango orchard mechanically pruned in trapezoidal form, the terminal branches and fruit production are concentrated in the West side of the plant and in the lower part of the canopy. The number of fruits per terminal branch is 1.15 .

What is the expected impact on horticulture?

- Since the worldwide mango fruit yield is low, even in the greater producer countries, the use of mechanical pruning in trapezoidal form may improve light exposition of branches, especially in the lower part of the canopy, where most fruits are produced. This result can improve mango production sustainability.

the production pruning, i.e., pruning the external portion of the canopy in all sides after fruit harvest has great importance because it stimulates a uniform re-growth so that all new branches have the same age, in order to induce uniform flowering.

Production pruning should be performed to promote a better light exposure of the plant canopy in order to improve light use by plants and higher photosynthetic rates (Sharma et al., 2006), especially because growth and reproductive strategies of mangoes are often connected to the morphology of axes and to their position within the plant architecture, but depending on mango cultivar (Normand et al., 2009).

Mango tree growth habit (upright, intermediate or spreading) depends on cultivar, thus branch density also varies as sparse, medium and dense (Majumder et al., 2011), but environmental conditions (Lima et al., 2018) and agronomic practices, especially for pruning (Sharma et al., 2006), have particular effects because the light penetration percentage may influence vegetative growth, flower initiation, fruit set, fruit retention and yield (Asrey et al., 2013).

Although growth and reproductive strategies of plants are often related to particular spatial distributions of branches within the plant architecture (Normand et al., 2009), this theme is poorly characterized and studied in the scientific literature, which justifies research projects, specifically for each mango cultivar grown in traditional and important pro- 
ducer areas such as São Francisco Valley in Brazil. A recent study was published by Palma and Retamales (2017), who observed that cane (Vaccinium corymbosum) productivity and fruit quality in highbush blueberry are affected by cane diameter and location within the canopy.

Hence, the present study aimed to evaluate the terminal branches density and fruit production in the canopy of high yield mango cv. 'Tommy Atkins' orchards grown in Brazilian semiarid climate.

\section{Materials and methods}

\section{Plant material and growth conditions}

Twenty-six-year-old mango (Mangifera indica L.) plants cv. 'Tommy Atkins' with uniform size and vigor were used.

The study was conducted from February to November 2016 in three experimental orchards located in Ibacém farm in Curaçá County $\left(08^{\circ} 59^{\prime} \mathrm{S}, 39^{\circ} 53^{\prime} \mathrm{W}\right.$ and $366 \mathrm{~m}$ a.s.l.), Bahia State, Brazil. The climate of this region is classified as BSwh (Köppen), which corresponds to a semiarid region. During the execution of the experiment the average air temperature and air humidity ranged from $20.07^{\circ} \mathrm{C}$ to $36.61^{\circ} \mathrm{C}$ and from $15.59 \%$ and $88.25 \%$, respectively, with total rainfall of $228.8 \mathrm{~mm}$

The plants, spaced $8 \mathrm{~m}$ between the rows and $5 \mathrm{~m}$ between the plants, were daily drip-irrigated with one emitter $\left(2.0 \mathrm{~L} \mathrm{~h}^{-1}\right)$ each $50 \mathrm{~cm}$. Three drip-irrigation pipe lines were placed in each mango row. All management practices such as pruning, control of weeds, pests and diseases, plant growth regulators for gibberellin inhibition (Cultar ${ }^{\circledR}$ ) and break dormancy (two first foliar sprays with potassium nitrate and then two foliar sprays with calcium nitrate) were performed following the instructions of Genú and Pinto (2002). The nutrient management was performed through a fertigation system, according to plant demand (Genú and Pinto, 2002). As can be seen in Figure 1, the production pruning was performed mechanically in order to reach a trapezoidal shape of the canopy as delimited by the dotted line, while the bottom of the canopy was manually pruned.

\section{Treatments and experimental design}

The experimental design consisted of randomized blocks with treatments defined as three parts of the canopy (upper, middle, or lower) and two plant sides (East and West), with eighteen replications and ten plants in each parcel. The experiment was repeated in four different orchards of the same farm and with the same characteristics for plants and edaphic-climatic conditions. The identification of the treatments in the plant can be visualized in Figure 1.

\section{Data gathered and statistical analysis}

All plants of the experiment were measured to determine the exact length of each part of the canopy, identified as upper, middle, and lower, as illustrated in Figure 1.

In each portion of the canopy (upper, middle, or lower) the number of terminal branches was determined according to the methodology described by Ramírez and Davenport (2010), and the terminal branches density (number of terminal branches $\mathrm{m}^{-2}$ ) was calculated.

The number of fruits in each part of the canopy was also recorded, but also in both plant sides (East and West, separately) (Ramírez et al., 2014). The fruit density in the canopy was calculated (number of fruits $\mathrm{m}^{-2}$ of the canopy). The number of fruits per terminal branch was also calculated by dividing the number of fruits by the number of branches.

The commercial fruit yield of the orchards $\left(t \mathrm{ha}^{-1}\right)$ was registered. Commercial fruits were manually harvested in a single day when they reached the physiological maturity which was characterized through pulp color (yellow cream), following the fruit selection parameter recommended by the Brazilian Program for Horticulture Modernization (2004) for commercial farms.

Mango plants were pruned in a trapezoidal shape and the canopy dimensions (base width, upper width, and canopy height, excluding trunk height) were measured for calculation of canopy area per hectare and fruit production per square meter of plant canopy. The parts of canopy without terminal branches available to perform the production pruning also were measured to calculate the plant canopy area without fruit production possibility.

Statistical analyses included analysis of variance (ANOVA) for separation of the different parts of the canopy and plant side using combined data of the three orchards. Data are presented as mean values and standard deviation (SD). All calculations were performed using the ASSISTAT 7.7 software, and terms were considered significant at $\mathrm{p}<0.01$.

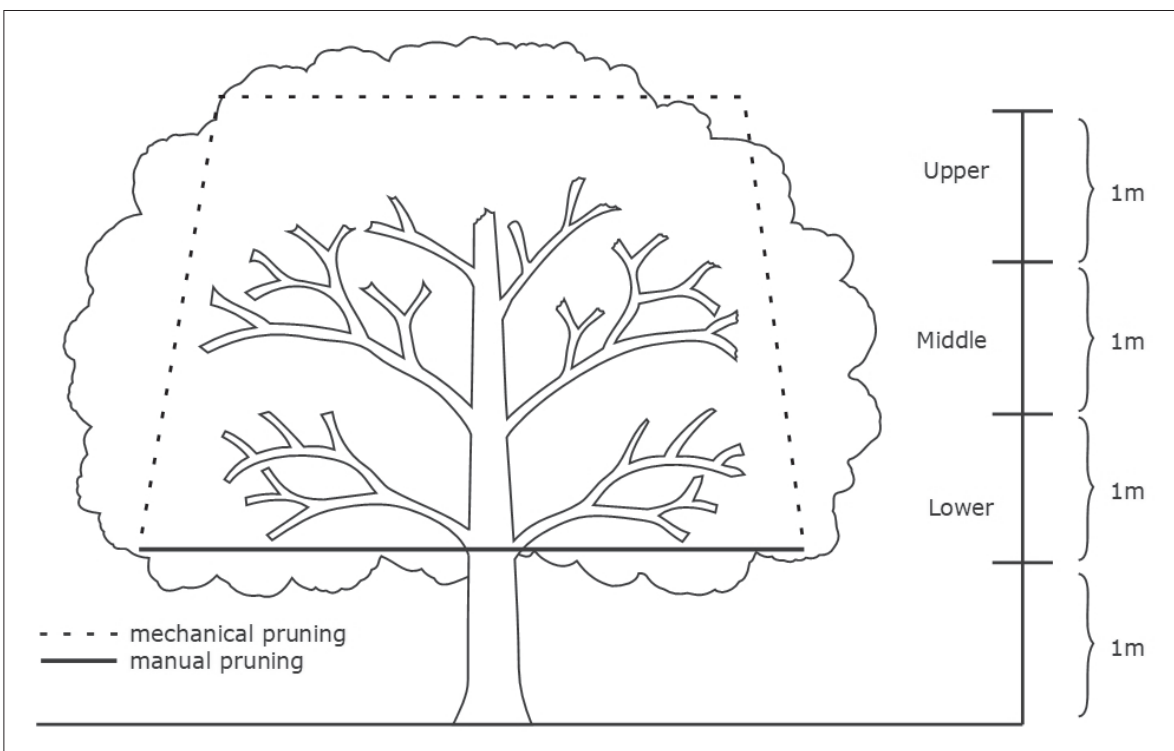

Figure 1. Pruning delineation in mango plant and visual expression of the treatments related to the branch position in the canopy (upper, middle, and lower). 


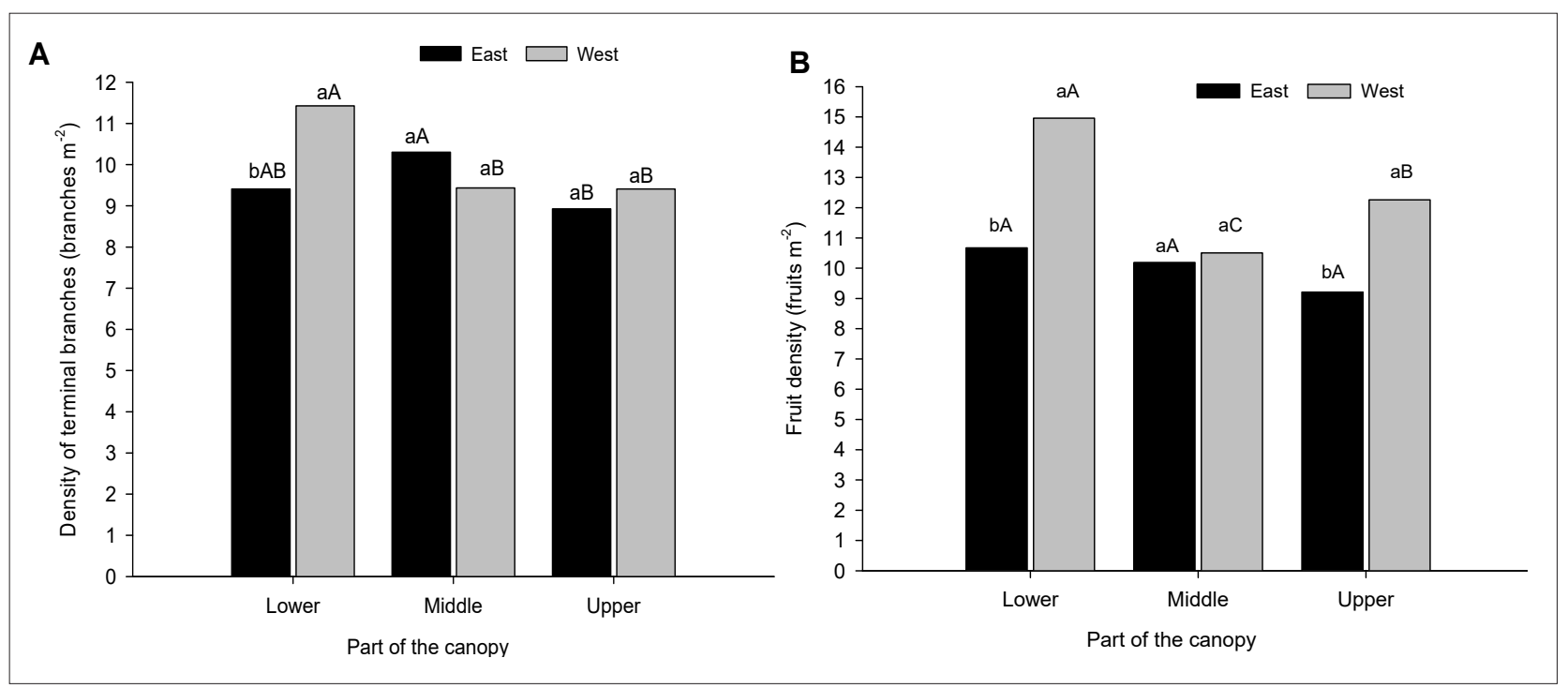

Figure 2. Density of terminal branch (A) and fruits (B) of mango cv. 'Tommy Atkins' according to plant side (East and West) and position in the canopy (upper, middle, and lower). Bars with capital letters compare part of the plant canopy (lower, middle, and upper), whereas bars with lowercase letters compare plant side (East and West). Bars with the same letters do not differ by Tukey's test at $5 \%$ probability.

\section{Results and discussion}

All variables studied in the present experiments were affected by plant canopy portion (upper, middle, or lower), while plant side (East and West) has no effect on terminal branch density. In addition, significant interactions for all variables were registered, showing interdependence between plant canopy and plant size.

The density of terminal branches (number of terminal branches $\mathrm{m}^{-2}$ of canopy) showed significant differences depending on plant canopy position and plant side interaction (Figure 2A). In the East side of the canopy the terminal branch density was $8.74 \%$ and $13.39 \%$ higher in the intermediate part of the canopy compared to lower and upper parts, respectively. On the other hand, in the West side of the canopy the lower part presented an average terminal branch density $17.70 \%$ higher than the middle and upper parts, which registered the same average value.

In a general observation of the three orchards it is possible to infer that mango plants pruned in the trapezoidal shape presented in each side (East and West) average base

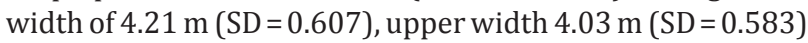
and canopy height $3.38 \mathrm{~m}(\mathrm{SD}=0.280)$, thus excluding trunk height. Whether excluded the calculated plant canopy areas without fruit production possibility, the vegetative canopy area of a single tree was $27.86 \mathrm{~m}^{2}$ (both plant sides) and the imperfections of plant canopy promoted a calculated free branch area of $3.8 \mathrm{~m}^{2}$ plant $^{-1}(\mathrm{SD}=0.351$ ). Thus, the orchards studied presented an effective vegetative area of $6732.5 \mathrm{~m}^{2}$ and $7.15 \mathrm{~kg}$ of fruits $\mathrm{m}^{-2}$, a first registration in the scientific literature for this measurement focused on a high-yield mango orchard and there is no recommended standard yet to compare with.

It is important to consider that 'Tommy Atkins' mango cultivar tree studied has a spreading attitude of main branches (UPOV, 2006), and in the present experiment production pruning was performed in a pyramidal form for better light exposure of the entire canopy (Figure 1). According to Léchaudel and Joas (2007), light exposure varies with position in the canopy, and the effect of light on photosynthesis includes both a direct effect of photosynthetic photon flux on the rate of electron flow and an indirect effect of light on leaf photosynthetic capacity, since plants allocate nitrogen resources within the canopy to enhance photosynthetic capacity in portions of the tree receiving high irradiances. Indeed, the lack of significant effect recorded for plant side on terminal branch density could be attributed to the more incisive function of training pruning on this variable.

According to Ramirez and Davenport (2016), the strong dominance of the terminal bud prevents lateral buds from emerging, an information that highlights the importance of performing the production pruning focusing higher terminal branches density, a fundamental key to reach high mango yields.

As can be seen in Figure 2A, in the lower part of the canopy the west side of the plant registered the higher density of terminal branch (Figure 2A). This result could be related to the time of plant exposition to light and the difference of light intensity between the plant sides studied (East or West). In this sense, Urban et al. (2003) argued that in a mango tree, photosynthetic acclimation to light is mainly determined by the mass-to-area ratio and to a lesser extent at low irradiance, by changes in the allocation of total leaf nitrogen, whereas changes in leaf nitrogen on a mass basis play a minor role; thus it is expected that the plant side exposed to such conditions also presents a better foliage formation and consequently, higher branch density. In addition, Asrey et al. (2013) reported that when mango plants are exposed to lower light incidence, leaf sprout is decreased and photosynthetic activity remains low.

Fruit density (number of fruits $\mathrm{m}^{-2}$ of canopy) depended on the interaction between plant position in the canopy and plant side (Figure 2B), but in both sides the higher fruit density was registered in the basal part of the plant, which recorded an average $4.5 \%$ and $29.76 \%$ higher than the middle part in East and West plant sides, respectively. In this sense, it is possible to affirm that the West side of the canopy was more incisive in fruit production compared to East one, with huge differences between the middle and the basal parts.

In fact the Western side of the canopy presented a higher fruit density compared to the Eastern part (Figure 3A). In 

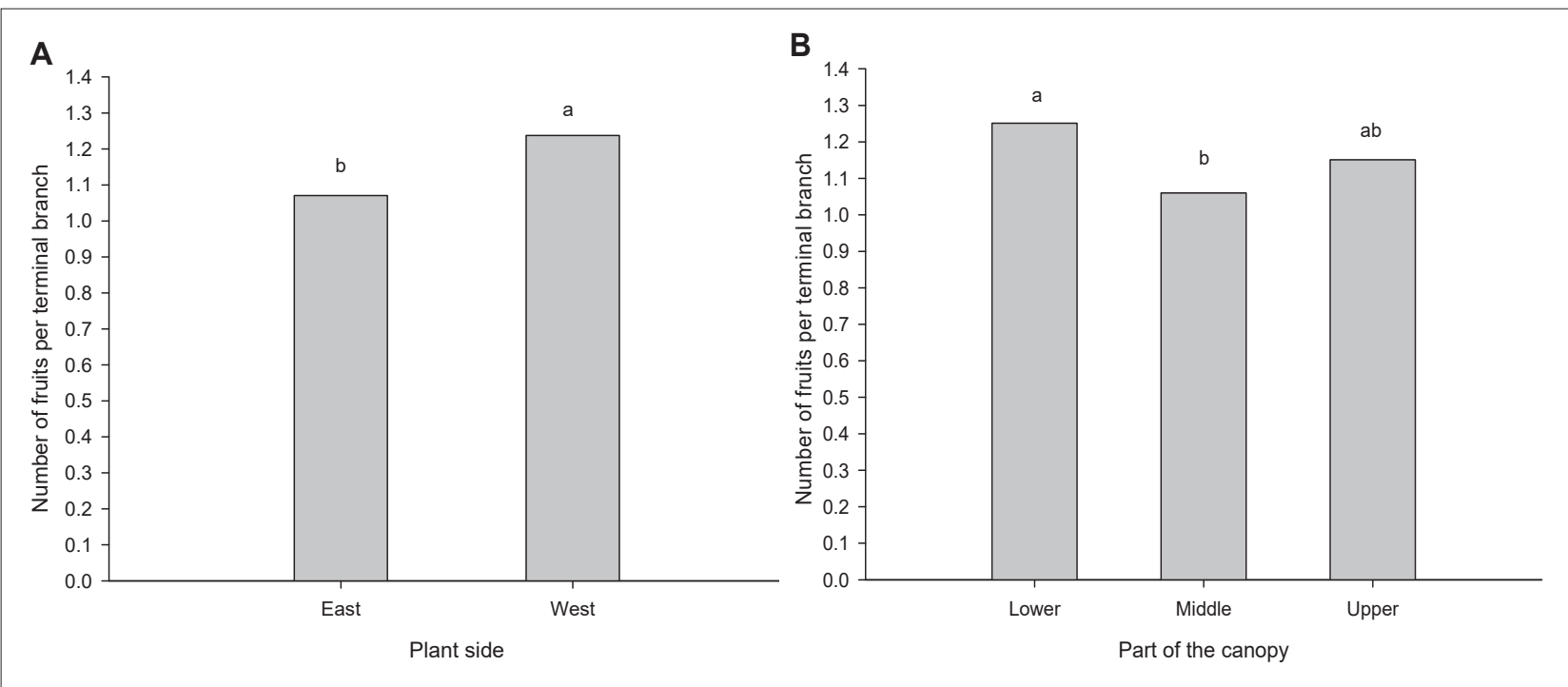

FIGURE 3. Number of fruits per terminal branch of mango cv. 'Tommy Atkins' according to plant side (A) and position in the canopy (B). Bars with different letters indicate significant differences by Tukey's test at 5\% probability [LSD(A): 0.08, LSD(B): 0.12]. LSD: least significant difference.

addition, this side of the plant also presented the higher density of terminal branch if compared to the East side (Figure 2A), which directly affects fruit density because according to Ramirez and Davenport (2010) individual panicles produce hundreds of ovule-bearing flowers, but only a small proportion of which set fruit and reach maturity. In this sense, Davenport et al. (2006) reported that there is requirement of light on the leaves for flowering under floral-inductive conditions, including branches exposed to less light intensity tend to produce vegetative branches whereas those branches exposed to full sunlight initiate only reproductive branches, and consequently more fruit production. Additionally, Asrey et al. (2013) concluded that sunlight not only influences the flowering and fruit set, but also enhances quality and color development, i.e., 'turning', of fruits.

In relation to the sunlight importance for flowering and fruit set of mangoes, Schaffer et al. (1994) concluded that shading can prevent or delay flower-bud formation, and a higher percentage of perfect flowers occurs on the side of the tree receiving direct sun or more light intensity. Mango trees have a significant number of shaded leaves and pruning can increase light penetration to these leaves (data not presented), but how this influences yield is unknown; possibly more light may result in larger fruit. Fruits also have a brighter red skin color under higher light.

The number of fruits per branch was affected by plant side and canopy portion, individually (Figure 3). The same tendency observed for fruit density in the canopy was also registered for the number of fruits per branch, i.e., higher average for the basal part $17.9 \%$ higher than the middle one). The average number of fruit per branch plotted in Figure 3 is compatible to the range of 1.0-2.2 fruits per fruiting growth unit recorded by Normand et al. (2009), who considered growth unit (GU), an elementary component of the axes forming the architectural unit.

It is important to infer that due to the trapezoidal shape of the canopy the upper part of the plant was subjected to a more severe pruning producing an effect on branch density.

As also observed for the other variables, the number of fruits per branch was significantly higher in the West side of the plant (Figure 3A), the side with more exposure to sunlight and, probably, with higher photosynthetic flux.

The results of the present study are important to serve as a basis on determination of what plant architecture could be really indicated to reach high yields of mango cv. "Tommy Atkins', since this is a crucial theme for a sustainability of mango farmers around the world. The general fruit yield average recorded in these presents $\left(48.16 \mathrm{t} \mathrm{ha}^{-1}\right)$ is much higher than those quoted in the scientific literature such as $27 \mathrm{t} \mathrm{ha}^{-1}$ (Cavalcante et al., 2016) and $35.6 \mathrm{t} \mathrm{ha}^{-1}$ (Barbosa et al., 2016) in Brazilian semiarid and $10.5 \mathrm{t} \mathrm{ha}^{-1}$ (Pleguezuelo et al., 2012) in Spain, as well as it is higher than the national average yields for the main worldwide producer countries such as Brazil (16.1 $\left.\mathrm{t} \mathrm{ha}^{-1}\right)$, China (8.2 $\left.\mathrm{t} \mathrm{ha}^{-1}\right)$, India (7.3 $\left.\mathrm{tha}^{-1}\right)$, and Mexico (8.9 $\mathrm{t} \mathrm{ha}^{-1}$ ) (FAO, 2017).

It is clear that fruit yield of mango cv. 'Tommy Atkins' is a result of plant architecture, branch density, fruit density, which depends on plant side (East or West) and their position in the canopy (lower, middle, or upper).

\section{Conclusion}

The results of this study indicate that in mango trees pruned in trapezoidal shape the branch density, the fruit density and the number of fruits per branch depend on plant side (East and West) and position in the canopy; terminal branches and fruit production is concentrated in the West side of the plant and in the lower part of the canopy, and the number of fruits per terminal branch is 1.15 .

\section{Acknowledgments}

Authors gratefully thank Ibacém farm (Curaçá County, Bahia State, Brazil) for structural support necessary for execution of the experiments.

\section{References}

Asrey, R., Patel, V., Barman, K., and Pal, R. (2013). Pruning affects fruit yield and postharvest quality in mango (Mangifera indica L.) cv. Amrapali. Fruits 68, 367-380. https://doi.org/10.1051/ fruits/2013082. 
Barbosa, L.F.S., Cavalcante, Í.H.L., and Lima, A.M.N. (2016) Desordem fisiológica e produtividade de mangueira cv. Palmer associada à nutrição de boro. Rev. Bras. Frutic. 38, 1-10. https://doi. org/10.1590/0100-2945-273/14.

Brazilian Program for Horticulture Modernization (2004). Standards Classification of Mango (São Paulo: Quality Center on Horticulture).

Cavalcante, Í.H.L., dos Santos, G.N.F., da Silva, M.A., Martins, R.S., Lima A.M.N., Modesto, P.I.R., Alcobia, A.M., Silva, T.R.S., Araujo e Amariz, R.A., and Beckmann-Cavalcante, M.Z. (2018). A new approach to induce mango shoot maturation in Brazilian semi-arid environment. J. Appl. Bot. Food Qual. 91, 281-286.

Davenport, D.L., Ying, Z., Kulkarni, V., and White, T.L. (2006). Evidence for a translocatable florigenic promoter in mango. Sci. Hortic. (Amsterdam) 110, 150-159. https://doi.org/10.1016/j. scienta.2006.06.029.

FAO, Food and Agriculture Organization of the United Nations (2017). Statistical database. http://faostat.fao.org/site/339/default.aspx.

Genú, P.J.C., and Pinto, A.C.A. (2002). A Cultura da Mangueira. (Brasília: Embrapa Informação Tecnológica).

Léchaudel, M., and Joas, J. (2007). An overview of preharvest factors influencing mango fruit growth, quality and postharvest behaviour. Braz. J. Plant Physiol. 19, 287-298. https://doi.org/10.1590/S167704202007000400004.

Lima, A., Cardoso, J., Cunha, T., Rodrigues, M., Hernani, L., Cunha, J., Amaral, A., and Neto, M. (2018). Changing in chemical and physical attributes of a sandy soil under irrigated mango cultivation in semiarid region. Comunicata Scientiae 8, 404-413. https://doi. org/10.14295/cs.v8i3.2544.

Majumder, D.A.N., Hassan, L., Rahim, M.A., and Kabir, M.A. (2011). Studies on physio-morphology, floral biology and fruit characteristics of mango. J. Bangladesh Agric. Univ. 9, 187-199. https://doi. org/10.3329/jbau.v9i2.10985

Normand, F., Bello, A.K., Trottier, C., and Lauri, P.E. (2009). Is axis position within tree architecture a determinant of axis morphology, branching, flowering and fruiting? An essay in mango. Annals of Botany 103, 1325-1336. https://doi.org/10.1093/aob/mcp079.

Palma, M.J., and Retamales, J.B. (2017). Cane productivity and fruit quality in highbush blueberry are affected by cane diameter and location within the canopy. Eur. J. Hortic. Sci. 82, 159-165. https:// doi.org/10.17660/eJHS.2017/82.4.1.

Pleguezuelo, C.R.R., Zuazo, V.H.D., Fernández, J.L.M., and Tarifa, D.F. (2012). Physico-chemical quality parameters of mango (Mangifera indica L.) fruits grown in a mediterranean subtropical climate (SE Spain). J. Agr. Sci. Technol. (Iran) 14, 365-374.

Ramirez, F., and Davenport, T.L. (2010). Mango (Mangifera indica L.) flowering physiology. Sci. Hortic. (Amsterdam) 126, 65-72. https:// doi.org/10.1016/j.scienta.2010.06.024.

Ramirez, F., and Davenport, T.L. (2016). Mango (Mangifera indica L.) pollination: A review. Sci. Hortic. (Amsterdam) 203, 158-168. https://doi.org/10.1016/j.scienta.2016.03.011.

Schaffer, B., and Andersen, P.C. (1994). Handbook of Environmental Physiology of Fruit Crops: Sub-tropical Crops (Boca Raton: CRC Press).

Sharma, R., and Singh, R. (2006). Effect of pruning intensity on light penetration and leaf physiology in Amrapali mango trees under highdensity planting. Trop. Sci. 46, 16-19. https://doi.org/10.1002/ ts.16.

UPOV, International Union for the Protection of New Varieties of Plants (2006). Guidelines for the Conduct of Tests for Distinctness, Uniformity and Stability: Mango. (Geneva: UPOV).
Urban, L., Le Roux, X., Sinoquet, H., Jaffuel, S., and Jannoyer, M. (2003). A biochemical model of photosynthesis for mango leaves: evidence for the effect of fruit on photosynthetic capacity of nearby leaves. Tree Physiol. 23, 289-300. https://doi.org/10.1093/ treephys/23.5.289.

VALEXPORT. Associação dos Produtores e Exportadores de Hortigranjeiros e Derivados do Vale do São Francisco. (2016). http://www.valexport.com.br.

Received: Feb. 9, 2018

Accepted: Oct. 28, 2019

Addresses of authors:

Í.H.L. Cavalcante ${ }^{1, *}$, L.E.C. de Sousa Ferraz ${ }^{2}$, J. Teixeira Lobo ${ }^{1}$ and J. Gomes da Cunha ${ }^{1}$

${ }^{1}$ Federal University of São Francisco Valley, Petrolina,

Pernambuco, Brazil

${ }^{2}$ Clorofila Agropecuária, Brazil

* Corresponding author;

E-mail: italo.cavalcante@univasf.edu.br 